\section{A Comprehensive Review of Pegvaliase, an Enzyme Substitution Therapy for the Treatment of Phenylketonuria}

\author{
Tasmina Hydery ${ }^{1}$ iD and Valerie Azzopardi Coppenrath² \\ 'Department of Family Medicine and Community Health, UMass Medical School_Clinical \\ Pharmacy Services (CPS), Shrewsbury, MA, USA. ${ }^{2}$ School of Pharmacy-Worcester/Manchester, \\ Massachusetts College of Pharmacy and Health Sciences (MCPHS) University, Worcester, MA, \\ USA.
}

Drug Target Insights

Volume 13: 1-8

(C) The Author(s) 2019

Article reuse guidelines:

sagepub.com/journals-permissions

DOI: $10.1177 / 1177392819857089$

(S)AGE

\begin{abstract}
OBJECTIVE: To review the pharmacology, pharmacokinetics, efficacy, safety, and place in therapy of a phenylalanine-metabolizing enzyme indicated to reduce blood phenylalanine concentrations, pegvaliase injection.
\end{abstract}

DATA SOURCES: Searches of MEDLINE (1946-September 1, 2018) were conducted using the terms pegvaliase and phenylalanine ammonia lyase (PAL). Additional data were obtained from the prescribing information, the product dossier obtained from the manufacturer, and Clinicaltrials.gov.

STUDY SELECTION AND DATA EXTRACTION: All English language articles related to pharmacology, pharmacokinetics, efficacy, or safety of the combination therapy in human subjects were reviewed.

DATA SYNTHESIS: Pegvaliase is a pegylated PAL enzyme that converts phenylalanine to ammonia and trans-cinnamic acid. Blood phenylalanine levels were reduced by approximately $50 \%$ to $70 \%$ in patients receiving therapeutic doses of pegvaliase. However, most patients experienced adverse events.

CONCLUSIONS AND RELEVANCE: The mainstay of therapy in phenylketonuria (PKU) has historically consisted of dietary restriction of phenylalanine. Pegvaliase injection is the first Food and Drug Administration (FDA)-approved enzyme substitution therapy for patients with PKU. The therapy may be a viable option for patients with documented blood phenylalanine $>600 \mu \mathrm{mol} / \mathrm{L}$ who have failed existing management strategies.

KEYWORDS: Palynziq, pegvaliase, phenylalanine ammonia lyase, pegvaliase-pqpz, phenylketonuria, PKU

RECEIVED: May 22, 2019. ACCEPTED: May 23, 2019.

TYPE: Review

FUNDING: The author(s) received no financial support for the research, authorship, and/or publication of this article.
DECLARATION OF CONFLICTING INTERESTS: The author(s) declared no potentia conflicts of interest with respect to the research, authorship, and/or publication of this article.

CORRESPONDING AUTHOR: Tasmina Hydery, Department of Family Medicine and Community Health, UMass Medical School-Clinical Pharmacy Services (CPS), Shrewsbury, MA 01545, USA. Email: tasmina.hydery@umassmed.edu

\section{Introduction}

Phenylketonuria (PKU) is a rare autosomal recessive condition affecting about 1 in 13500 to 19000 people in the United States. ${ }^{1}$ Phenylketonuria is diagnosed through detection of elevated blood phenylalanine concentration. ${ }^{2}$ If untreated, PKU can cause chronic intellectual, neurodevelopmental, and psychiatric disabilities. Excessive phenylalanine is thought to interfere with brain growth, myelination, and neurotransmitter synthesis. Most cases of PKU are detected shortly after birth by newborn screening. As a result, the severe signs and symptoms of classic PKU are rarely seen. ${ }^{2}$

Elevated phenylalanine levels are caused by a deficiency in the enzyme, phenylalanine hydroxylase $(\mathrm{PAH}){ }^{2}$ The spectrum of severity in untreated PKU ranges from complete enzyme deficiencyorclassicPKU(phenylalanineconcentration $>1200 \mu \mathrm{mol} / \mathrm{L}$ ), moderate PKU (phenylalanine concentration $=900-1200 \mu \mathrm{mol} / \mathrm{L}$ ), mild PKU (phenylalanine concentration $=600-900 \mu \mathrm{mol} / \mathrm{L}$ ), and mild hyperphenylalaninemia (HPA) (phenylalanine concentration $=360-600 \mu \mathrm{mol} / \mathrm{L}){ }^{3}$ Although guidelines recommend lifelong treatment to a target blood phenylalanine level of 120 to
$360 \mu \mathrm{mol} / \mathrm{L}^{4,5}$ or 120 to $600 \mu \mathrm{mol} / \mathrm{L}$, (van Wegberg, MacDonald and Ahring, 2017) therapy must be individualized to each patient.

Management of patients with HPA and PKU should be provided by an interdisciplinary team of nutritionists, psychologists, social workers, and metabolic specialists. ${ }^{2}$ Phenylketonuria is a relatively rare disease and patients may require lifelong treatment. The goal of therapy is to lower blood phenylalanine concentrations to minimize the neurocognitive and psychiatric effects of PKU. ${ }^{4-7}$ The mainstay of therapy is dietary restriction of phenylalanine and supplementation with phenylalanine-free medical foods to avoid nutritional deficits. ${ }^{4-6}$ The medical foods are protein substitutes that are phenylalanine-free and fortified in tyrosine and may contain glycomacropeptides and other large neutral amino acids as the protein source. ${ }^{3}$ Adherence to the restrictive diet requires planning and organization, and can be challenging for patients. ${ }^{4}$

Sapropterin was Food and Drug Administration (FDA)approved on December 13, 2007, and was the first pharmacologic therapy for treatment of PKU. ${ }^{8}$ It is an oral PAH cofactor 
Table 1. Summary of pharmacokinetic parameters studied.

\begin{tabular}{|c|c|c|}
\hline \multirow[t]{2}{*}{ PHARMACOKINETIC PARAMETER } & \multicolumn{2}{|c|}{ DAILY MAINTENANCE DOSAGE } \\
\hline & PEGVALIASE $20 \mathrm{MG}$ & PEGVALIASE $40 \mathrm{MG}$ \\
\hline Median $\mathrm{T}_{\max }$ & 8 hours & \\
\hline $\mathrm{C}_{\max }$ at steady state $($ mean $\pm \mathrm{SD})$ & $14.0 \pm 16.3 \mathrm{mg} / \mathrm{L}$ & $16.7 \pm 19.5 \mathrm{mg} / \mathrm{L}$ \\
\hline Apparent volume of distribution (mean $\pm \mathrm{SD}$ ) & $26.4 \pm 64.8 \mathrm{~L}$ & $22.2 \pm 19.7 \mathrm{~L}$ \\
\hline Apparent clearance at steady state (mean \pm SD) & $0.39 \pm 0.87 \mathrm{~L} / \mathrm{h}$ & $1.25 \pm 2.46 \mathrm{~L} / \mathrm{h}$ \\
\hline Half-life (mean $\pm S D)$ & $47 \pm 42$ hours & $60 \pm 45$ hours \\
\hline Steady state plasma concentrations during maintenance treatment (mean $\pm \mathrm{SD}$ ) & $11.2 \pm 9.0 \mathrm{mg} / \mathrm{L}$ & $10.4 \pm 12.7 \mathrm{mg} / \mathrm{L}$ \\
\hline Metabolism & $\begin{array}{l}\text { Catabolic pathways, } \\
\text { and amino acids }\end{array}$ & d into small peptides \\
\hline
\end{tabular}

Abbreviations: $C_{\max }$, peak concentration; $T_{\max }$, time to peak concentration.

indicated to reduce blood phenylalanine concentrations in patients with HPA due to tetrahydrobiopterin (BH4)responsive PKU. Sapropterin is used in conjunction with a phenylalanine-restricted diet. ${ }^{9}$ The efficacy of sapropterin is based on the presence of residual PAH enzymatic activity. Approximately $25 \%$ to $50 \%$ of patients with PKU respond to sapropterin. ${ }^{4}$

Phase 3 trials for an enzyme substitution therapy for PKU began in 2013 and showed promise to be effective in any patient with PKU regardless of residual enzymatic activity. ${ }^{4}$ Pegvaliase, FDA-approved on May 24, 2018, acts as a substitute for the deficient PAH enzyme. ${ }^{10}$ Pegvaliase is indicated to reduce blood phenylalanine concentrations in adult patients with PKU who have uncontrolled blood phenylalanine concentrations $>600 \mu \mathrm{mol} / \mathrm{L}$ on existing management. ${ }^{11,12}$

Adult patients with PKU whose phenylalanine levels are not appropriately managed may experience adverse neurocognitive and psychiatric outcomes. ${ }^{7}$ The objective of this article is to review the pharmacology, pharmacokinetics, efficacy, safety, and place in therapy of pegvaliase injection. It will also provide an overview of the role of pegvaliase compared with current standard of care.

\section{Data Sources}

A search of MEDLINE (1946-September 1, 2018) was conducted using the terms pegvaliase and phenylalanine ammonia lyase (PAL). The 2 terms were combined with the Boolean operator OR. The term pegvaliase was also searched on its own. All English language articles related to pharmacology, pharmacokinetics, efficacy, or safety of the therapy in human subjects were included. The references of included articles were searched to identify additional sources. The product dossier was obtained from the manufacturer, and additional data were obtained from the prescribing information and Clinicaltrials.gov.

\section{Data Synthesis \\ Pharmacology}

PAH catalyzes the irreversible conversion of phenylalanine to tyrosine. In the absence of PAH in PKU, dietary phenylalanine is unable to be converted to tyrosine and undergoes further processing to metabolites including L-dopa, thyroxine, dopamine, noradrenaline, adrenaline, and melanin. ${ }^{13}$ There are 2 modes of enzyme therapy through replacement of the PAH enzyme or substitution with another enzyme to degrade excess phenylalanine. ${ }^{12}$ Pegvaliase follows the latter category and is a pegylated PAL enzyme that converts phenylalanine to ammonia and trans-cinnamic acid. ${ }^{8}$ Ammonia is metabolized by the liver. Trans-cinnamic acid and its final product, benzoic acid, are conjugated with glycine and excreted in the urine. ${ }^{13,14}$

\section{Pharmacokinetics}

Due to the heterogeneity of immune response in adults with PKU, the pharmacokinetics of pegvaliase exhibit high interpatient and intrapatient variability. High antibody titers correlated with higher apparent clearance. The pharmacokinetic parameters are summarized in Table 1.

\section{Clinical Trials}

\section{Phase 1}

Clinical trial experience with pegvaliase is summarized in Table 2. The first study of pegvaliase in humans was a phase 1 , multicenter, open-label study in patients over the age of 18 with a diagnosis of classic PKU (phenylalanine concentration $>1200 \mu \mathrm{mol} / \mathrm{L}$ at diagnosis) and had a history of poor dietary compliance (PAL-001, NCT00634660). The average baseline phenylalanine concentration was $1310 \mu \mathrm{mol} / \mathrm{L}$, and the average body mass index (BMI) was $26.4 \mathrm{~kg} / \mathrm{m}^{2}$. Twenty-five patients were recruited from 7 centers in the United States. Patients were 
Table 2. Summary of trials of pegvaliase for the treatment of PKU in adults.

\begin{tabular}{|c|c|c|c|c|c|c|}
\hline PHASE & IDENTIFIER & DESIGN & DURATION & DOSING & $\mathrm{N}$ & RESULTS \\
\hline 1 & $\begin{array}{l}\text { NCT00634660 } \\
\text { (PAL-001) }\end{array}$ & OL, single dose & 42 days & $\begin{array}{l}0.001,0.003,0.10,0.03 \\
\text { and } 0.100 \mathrm{mg} / \mathrm{kg}\end{array}$ & 25 & $\begin{array}{l}48.3 \% \text { reduction in Phe from day } 4 \text { to } 7 \\
\text { in the highest dosing group }\end{array}$ \\
\hline 2 & $\begin{array}{l}\text { NCT00925054 } \\
\text { (PAL-002) }\end{array}$ & $\begin{array}{l}\text { OL, multiple dose } \\
\text { with induction and } \\
\text { titration phases }\end{array}$ & 16 weeks & $\begin{array}{l}0.001-0.1 \mathrm{mg} / \mathrm{kg} \text { given } 5 \mathrm{~d} / \\
\text { wk }\end{array}$ & 40 & $\begin{array}{l}\text { No significant changes in Phe } \\
5 \% \text { ( } 2 \text { patients) discontinued due to } \\
\text { AEs }\end{array}$ \\
\hline 2 & $\begin{array}{l}\text { NCT01212744 } \\
\text { (PAL-004) }\end{array}$ & OL, multiple dose & 13 weeks & $\begin{array}{l}0.06-0.8 \mathrm{mg} / \mathrm{kg} / \mathrm{d} \text { given } \\
5 \mathrm{~d} / \mathrm{wk}\end{array}$ & 16 & $\begin{array}{l}\text { No significant changes in Phe } \\
6.25 \% \text { (1 patient) discontinued due to } \\
\text { AEs }\end{array}$ \\
\hline 2 & $\begin{array}{l}\text { NCT01560286 } \\
(165-205)\end{array}$ & $\begin{array}{l}\mathrm{OL} \text {, multiple dose } \\
\text { with induction, } \\
\text { titration, and } \\
\text { maintenance } \\
\text { phases }\end{array}$ & 24 weeks & $\begin{array}{l}2.5 \mathrm{mg} \text { weekly } \times \\
4-8 \text { weeks, then increased } \\
\text { to a maximum of } 75 \mathrm{mg} \\
\text { daily }\end{array}$ & 24 & $\begin{array}{l}46 \% \text { reached maintenance dose } \\
56 \% \text { reduction in Phe } \\
54 \% \text { did not reach maintenance dose } \\
8.33 \% \text { ( } 2 \text { patients) discontinued due to } \\
\text { AEs }\end{array}$ \\
\hline 2 & $\begin{array}{l}\text { NCT00924703 } \\
\text { (PAL-003) }\end{array}$ & $\begin{array}{l}\text { OL, multiple dose } \\
\text { extension study }\end{array}$ & $\begin{array}{l}\text { Extended } \\
\text { follow-up of } \\
\text { phase } 2 \\
\text { studies to } \\
264 \text { weeks }\end{array}$ & $\begin{array}{l}\text { Continued or increased } \\
\text { from parent studies, up to } \\
375 \mathrm{mg} / \mathrm{wk} \text { given up to } 7 \mathrm{~d} / \\
\text { wk }\end{array}$ & $68^{a}$ & $\begin{array}{l}58.9 \% \text { reduction in Phe at } 48 \text { weeks } \\
72.3 \% \text { reduction in Phe at } 120 \text { weeks } \\
5.9 \% \text { (4 patients) discontinued due to } \\
\text { AEs }\end{array}$ \\
\hline 3 & $\begin{array}{l}\text { NCT01819727 } \\
\text { (PRISM-1) }\end{array}$ & $\begin{array}{l}\text { OL, randomized } \\
\text { multiple dose with } \\
\text { induction, titration, } \\
\text { and maintenance } \\
\text { phases }\end{array}$ & 24 months & $\begin{array}{l}2.5 \mathrm{mg} \text { daily titrated to } \\
\text { either } 20 \text { or } 40 \mathrm{mg} \text { daily }\end{array}$ & 261 & $\begin{array}{l}51.1 \% \text { reduction in Phe at } 12 \text { months } \\
68.7 \% \text { reduction in Phe at } 24 \text { months } \\
\text { Improvement in mood and inattention } \\
\text { scores } \\
11 \% \text { ( } 29 \text { patients) discontinued due to } \\
\text { AEs }\end{array}$ \\
\hline \multirow[t]{5}{*}{3} & $\begin{array}{l}\text { NCT01889862 } \\
\text { (PRISM-2) }\end{array}$ & $\begin{array}{l}\text { PRISM-1 extension } \\
\text { studyb }\end{array}$ & & & & \\
\hline & Part 1 & $\begin{array}{l}\text { OL continuation of } \\
\text { PRISM-1 }\end{array}$ & & 20 or 40 mg daily & & Data not published \\
\hline & Part 2 & $\begin{array}{l}\text { R discontinuation } \\
\text { study }\end{array}$ & 8 weeks & $\begin{array}{l}20 \mathrm{mg} \text { daily, } 40 \mathrm{mg} \text { daily, } \\
\text { or placebo }\end{array}$ & 86 & $\begin{array}{l}\text { No change in Phe in the groups that } \\
\text { maintained doses } \\
62.6 \% \text { increase in Phe in placebo } \\
20 \mathrm{mg} \text { group } \\
56.4 \% \text { increase in Phe in placebo } \\
40 \mathrm{mg} \text { group } \\
\text { No patients discontinued due to AEs }\end{array}$ \\
\hline & Part 3 & OL, PD, PK & & 20 or $40 \mathrm{mg}$ daily & & Data not published \\
\hline & Part 4 & OL extension & Ongoing & 5-60 mg daily & & Ongoing \\
\hline
\end{tabular}

Abbreviations: AEs, adverse events; OL, open label; PD, pharmacodynamics; Phe, phenylalanine; PK, pharmacokinetic; PKU, phenylketonuria; R, randomized.

aPatients from the other phase 2 studies.

b12 patients from the phase 2 studies, but their data are not reported.

excluded if they had renal or hepatic dysfunction, had pregnancy or potential pregnancy, or used nicotine, drugs of abuse, or any investigational products in the 30 days prior to screening. ${ }^{15}$

Twenty-five patients were assigned to 1 of 5 dosing groups in which they received a single subcutaneous injection of pegvaliase on day 1: $0.001,0.003,0.10,0.03$, and $0.100 \mathrm{mg} / \mathrm{kg}$. Patients were followed up for 42 days. In the patients who received the $0.1 \mathrm{mg} / \mathrm{kg}$ dose, pegvaliase significantly reduced phenylalanine concentrations (1113 to $575 \mathrm{mmol} / \mathrm{L}$, mean reduction of $48.3 \%$ ) on day 6 . Phenylalanine concentrations increased from day 7 to day 21 and remained relatively consistent through the end of the study. ${ }^{15}$

\section{Phase 2}

The optimal dosing regimens were explored in 3 phase 2 studies of pegvaliase. PAL-002 (NCT00925054) was an openlabel, multicenter study of 40 adults with PKU. Patients entered an 8-week induction phase of various fixed and weight-based doses of pegvaliase administered weekly, followed by an 8-week titration phase during which increasing doses of pegvaliase were administered weekly with the goal of achieving reduced blood phenylalanine concentrations. The doses ranged from 0.001 to $0.1 \mathrm{mg} / \mathrm{kg}$ throughout the study. These doses were not sufficient to lower phenylalanine concentrations. 
PAL-004 (NCT01212744) was an open-label, multicenter study of 16 adults with PKU. Patients were given doses of pegvaliase $5 \mathrm{~d} / \mathrm{wk}$ which ranged from 0.06 to $0.8 \mathrm{mg} / \mathrm{kg}$ throughout the 13 weeks of the study. Similar to PAL-002, the doses studied resulted in inadequate control of blood phenylalanine levels. All patients in both studies experienced at least 1 adverse event (AE). The regimens used in PAL-002 were generally well tolerated, but the higher doses in PAL-004 were associated with more frequent hypersensitivity reactions (which included arthralgia, arthritis, eye inflammation, eye irritation, eye pain, joint stiffness, joint swelling, pyrexia, vision blurred, and polyarthritis) and the need for dose reduction. ${ }^{16}$

Based on observations made in PAL-002 and PAL-004, a third phase 2 study, 165-205 (NCT01560286), was conducted. This study was an open-label, multicenter study that was 24 weeks in duration. Patients were eligible if they had a blood phenylalanine concentration of $\geqslant 600 \mu \mathrm{mol} / \mathrm{L}$ at screening and an average concentration of $\geqslant 600 \mu \mathrm{mol} / \mathrm{L}$ in the 6 months prior to the screening, and no prior treatment with sapropterin in the 4 months prior to screening. Patients who were pregnant, planning to become pregnant, or breastfeeding were excluded. Patients entered a 4- to 8-week induction phase of $2.5 \mathrm{mg} / \mathrm{wk}$. Afterward, the dose and frequency could be increased over a minimum of 4 weeks to attain a blood phenylalanine concentration of $\leqslant 600 \mu \mathrm{mol} / \mathrm{L}$. The authors defined the "maintenance dose" as the regimen that resulted in target concentrations for 4 weeks without the need for dose adjustments. Once the maintenance dose was determined, patients entered the next phase. In the maintenance phase, the maintenance dose was continued but could still be adjusted for safety or to maintain concentrations below $600 \mu \mathrm{mol} / \mathrm{L}$. The maximum dose in the maintenance phase was $75 \mathrm{mg} / \mathrm{d}$ given $5 \mathrm{~d} / \mathrm{wk}$. However, the protocol was updated to change the maximum frequency to $7 \mathrm{~d} / \mathrm{wk}$. Patients experiencing severe hypersensitivity adverse events (HAEs) had their dosing interrupted or adjusted and restarted at the same or a lower dose. Another protocol change allowed patients with treatment-related acute systemic hypersensitivity events to permanently discontinue the study drug. The investigators used a modified intention-to-treat analysis consisting of participants who received at least 1 dose of the study drug and had at least 1 post-treatment blood phenylalanine level. ${ }^{17}$

Twenty-four patients enrolled in the study, with 11 patients achieving maintenance dose in the first 24 weeks (group A) and 13 patients not achieving maintenance dose within 24 weeks (group B). Patients had a mean age of approximately 29 years, and baseline blood phenylalanine concentrations were similar in both groups $(1134.8 \mu \mathrm{mol} / \mathrm{L}$ in group $A$ vs $1197.5 \mu \mathrm{mol} / \mathrm{L}$ in group B). However, group A was comprised mostly of women with a mean weight of $64.6 \mathrm{~kg}$, whereas group B was mostly men with a mean weight of $86.4 \mathrm{~kg}$. Baseline total protein intake and dietary phenylalanine intake were higher in group B. Mean doses of pegvaliase in the 24-week study were $64.7 \mathrm{mg}$ in group A and $89.4 \mathrm{mg}$ in group B. The group A patients' mean blood phenylalanine concentration reached $<600 \mu \mathrm{mol} / \mathrm{L}$ by week 11 of the study. The mean reduction from baseline was $627 \pm 432 \mu \mathrm{mol} / \mathrm{L}$ ( $56 \% \pm 36 \%$ reduction). Furthermore, all patients in group A reached a blood phenylalanine concentration target of $<120 \mu \mathrm{mol} / \mathrm{L}$ during the 24 -week study. Group A had lower anti-drug antibody responses, which was likely associated with less immune-related clearance compared with patients in group B with higher anti-drug antibody responses. Ten of the 13 patients in group B continued on to the extension study, during which they achieved a blood phenylalanine concentration of $\leqslant 600 \mu \mathrm{mol} / \mathrm{L}$ by week $48 .{ }^{17}$

Patients in the 3 phase 2 dosing finding studies (will be referred to hereon in as "parent studies") were invited to continue on in an extension study (PAL-003, NCT00924703) if they were willing to continue stable protein intake. Patients taking any other injectable drug containing polyethylene glycol (PEG) and patients with a history of systemic hypersensitivity events to a PEG-containing product were excluded. However, patients with a previous reaction to pegvaliase could be eligible for the study on a case by case basis. Doses for individuals were either continued from the parent study or increased and were adjusted throughout the study to attain or maintain phenylalanine concentrations between 60 and $600 \mu \mathrm{mol} / \mathrm{L}$. In addition, doses could be adjusted to manage AEs. Initially, dosing ranged from 2.5 to $375 \mathrm{mg} / \mathrm{wk}$ or 0.001 to $5 \mathrm{mg} / \mathrm{kg} / \mathrm{wk}$, but a protocol changed limited weekly dosing to $375 \mathrm{mg} / \mathrm{wk}$. The authors used a modified intention-totreat analysis for efficacy which included all patients who received 1 dose of pegvaliase and had at least 1 phenylalanine concentration measurement taken after treatment. ${ }^{17}$

Sixty-eight of the 80 participants in the parent studies enrolled in the extension study. The baseline phenylalanine concentration was $1022.4 \mu \mathrm{mol} / \mathrm{L}$. The mean daily dose of pegvaliase in the parent studies was $5.3 \mathrm{mg} / \mathrm{d}(\mathrm{SD}=6.8 \mathrm{mg} / \mathrm{d})$, and this increased to $26.2 \mathrm{mg} / \mathrm{d} \quad(\mathrm{SD}=17.9 \mathrm{mg} / \mathrm{d})$ in the extension study. Doses remained relatively stable from week 48 to week 120 of the study. The average duration of treatment in all of the phase 2 studies was approximately 3.4 years. Mean phenylalanine concentrations decreased throughout the study by more than half $(58.9 \%)$ at week 48 of treatment and by $72 \%$ at week $120(1022.4 \mu \mathrm{mol} / \mathrm{L}$ at baseline, $541.6 \mu \mathrm{mol} / \mathrm{L}$ at week 48 , and $372 \mu \mathrm{mol} / \mathrm{L}$ at week 120). ${ }^{17}$

Approximately one-third of patients (36.8\%) had their pegvaliase dosing reduced or held during the study. A small number of patients $(n=4,5.9 \%)$ discontinued the study due to AEs. All 4 patients reported resolution of the AEs after discontinuing treatment. Hypersensitivity adverse events were highest during early treatment in phase 2 studies and correlated with the timing of highest IgM, PEG IgM, and PEG IgG antibodies. ${ }^{17}$

\section{Phase 3}

Pegvaliase was evaluated in a phase 3 study, PRISM-1 (NCT01819727).In this multicenter, open-label study, patients 
naïve to pegvaliase were randomized to receive 1 of 2 regimens of pegvaliase. Patients with a blood phenylalanine concentration of $600 \mu \mathrm{mol} / \mathrm{L}$ or higher for at least 6 months prior to the study were eligible. It is unclear if allocation to treatment groups was concealed. Both groups received $2.5 \mathrm{mg}$ once per week of pegvaliase subcutaneously for 4 weeks during the induction period. Dosing and frequency were increased gradually to either $20 \mathrm{mg} / \mathrm{d}$ or to $40 \mathrm{mg} / \mathrm{d}$. Titration was performed over a period of 5 to 30 weeks. The schedule was described for the $20 \mathrm{mg} / \mathrm{d}$ group: $2.5 \mathrm{mg}$ twice weekly, $10 \mathrm{mg}$ weekly, $10 \mathrm{mg}$ twice weekly, $10 \mathrm{mg} 4$ times weekly, $10 \mathrm{mg}$ daily, and then $20 \mathrm{mg}$ daily. Doses were continued in the maintenance phase, which ranged from 24 to 36 weeks in duration. Phenylalanine levels, safety, immunogenicity, and neuropsychiatric symptoms were assessed by trained study staff at each site using tools validated for use in PKU. ${ }^{18}$

PRISM-1 included 261 patients: 131 in the $20 \mathrm{mg} / \mathrm{d}$ group and 130 in the $40 \mathrm{mg} / \mathrm{d}$ group. Patients had a mean age of approximately 30 years at baseline and were mostly white, and approximately half of them were women. Mean phenylalanine levels at baseline were $1232.7 \mu \mathrm{mol} / \mathrm{L}$. The mean number of weeks to reach maintenance doses was 11.5 and 14 in the $20 \mathrm{mg} / \mathrm{d}$ and $40 \mathrm{mg} / \mathrm{d}$ groups, respectively. ${ }^{18}$

Mean phenylalanine concentrations decreased by $51.1 \%$ from baseline to $564.5 \mu \mathrm{mol} / \mathrm{L}$ at 12 months of follow-up, and by $68.7 \%$ from baseline to $311.4 \mu \mathrm{mol} / \mathrm{L}$ at 24 months of follow-up. Inattention and mood scores improved while on treatment with pegvaliase and correlated with a decrease in phenylalanine levels. Similar to previous studies, all patients experienced at least $1 \mathrm{AE}$. However, in this study, 99\% of events were mild to moderate in nature, and $96 \%$ resolved without dose reduction or interruption. This represents an improvement in the safety profile compared with previous regimens studied. The most common AEs were arthralgia (70.5\%), injection site reactions (62.1\%), injection site erythema (47.9\%), and headache (47.1\%). Of the AEs leading to discontinuation, $2.7 \%$ were anaphylaxis, $2.7 \%$ were arthralgia, $1.1 \%$ were injection site reactions, and $0.8 \%$ were generalized rash. Twelve patients $(4.6 \%)$ experienced 1 or more acute systemic HAEs which were independently adjudicated by an allergist/immunologist. The median time after pegvaliase administration to acute systemic HAE was 1.8 minutes, and all occurred within the first 50 days of dosing and were resolved quickly. ${ }^{18}$

Patients enrolled in PRISM-1 could continue to PRISM-2 (NCT01889862), a study to evaluate the safety and efficacy of long-term treatment. Patients reaching maintenance dosing in PRISM-1 entered part 1 of PRISM-2, and continued their assigned doses, either $20 \mathrm{mg}$ or $40 \mathrm{mg}$ daily. Part 2 was a randomized, double-blinded, placebo-controlled discontinuation study which will be described below. Part 3 was an open-label pharmacodynamics and pharmacokinetic study, and part 4 is an open-label extension study which is ongoing. Patients who did not reach maintenance dosing in PRISM-1 could enter directly in to part 4 of PRISM-2, in which the open-label dosing ranges from 5 to $60 \mathrm{mg}$ daily. ${ }^{18}$

Eighty-six patients who received pegvaliase in PRISM-2 part 1 enrolled in the double-blinded PRISM-2 part 2 discontinuation trial. An additional 9 patients were enrolled but were not included in the efficacy analysis. Patients were randomized via concealed allocation to receive either their current pegvaliase dose (either 20 or $40 \mathrm{mg} / \mathrm{d}$ ) or matched placebo containing either $20 \mathrm{mg}$ or $40 \mathrm{mg}$ of Dextran 40 (22\% Dextran 40 ). The study drugs were self-administered daily for 8 weeks, rotating subcutaneous injection sites. ${ }^{19}$

The pooled active pegvaliase group phenylalanine concentrations remained stable from baseline to week 8 (503.9$559 \mu \mathrm{mol} / \mathrm{L})$, while levels in both placebo groups increased $(563.9-1509 \mu \mathrm{mol} / \mathrm{L}$ in the placebo $20 \mathrm{mg}$ group and 508.2$1164.4 \mu \mathrm{mol} / \mathrm{L}$ in the placebo $40 \mathrm{mg}$ group). However, no significant changes in mood or inattention were observed, perhaps due to the short duration of the trial or to the tools used to measure these symptoms in the trial. ${ }^{19}$ Patients in PRISM-1 demonstrated improvements in attention deficit hyperactivity disorder (ADHD) scores at 3 months of treatment. ${ }^{16}$

Overall, clinical trial experience from phase 1 to phase 3 suggests substantial reductions in blood phenylalanine concentrations and improvement in inattention and mood symptoms with the use of pegvaliase. However, these benefits must be weighed against the risk of common and sometimes serious AEs.

\section{Dosing and Administration}

The package insert for Palynziq recommends to obtain baseline blood phenylalanine concentrations prior to treatment initiation. ${ }^{11}$ The induction dosage for pegvaliase is $2.5 \mathrm{mg}$ subcutaneously once weekly for 4 weeks under the supervision of a health care provider. The dosage should be titrated based on tolerability over at least 5 weeks to achieve a dosage of $20 \mathrm{mg}$ subcutaneously once daily. Therapeutic response may not be achieved until the patient is titrated to an effective maintenance dose.

During treatment, patient tolerability, blood phenylalanine concentrations, dietary protein, and phenylalanine intake should be monitored. Studies in adult PKU patients have shown a variation in phenylalanine levels can be observed without any change in treatment. ${ }^{20}$ In clinical trials, the response to sapropterin treatment was defined as a $30 \%$ reduction in blood phenylalanine concentration from baseline. ${ }^{21}$ In contrast, therapeutic response with pegvaliase was based on a $20 \%$ reduction in blood phenylalanine concentration from baseline or a blood phenylalanine concentration $\leqslant 600 \mu \mathrm{mol} / \mathrm{L}$ after 24 weeks. If not achieved, increasing the pegvaliase dose to a maximum dosage of $40 \mathrm{mg}$ subcutaneously once daily can be considered. If therapeutic response has not been achieved after 16 weeks on the maximum dosage, discontinuation of pegvaliase is recommended. If 
patients experience blood phenylalanine concentrations $<30 \mu \mathrm{mol} / \mathrm{L}$ during titration and maintenance, the dosage of pegvaliase may be reduced or the dietary protein and phenylalanine intake may be modified. ${ }^{11}$

For hypersensitivity reactions, premedication can be considered with an H1-receptor antagonist, H2-receptor antagonist, and/or antipyretic prior to administration based on tolerability. Patients should be observed during and for at least 60 minutes after receiving pegvaliase injection. Patients should also be trained on recognition of signs and symptoms of anaphylaxis, how to administer injectable epinephrine, and how to seek emergency care, if needed. If the decision is made to readminister pegvaliase after an episode of anaphylaxis, the subsequent dose should be administered under the supervision of a health care provider after titrating based on patient tolerability and therapeutic response. ${ }^{11}$

Due to the risks of anaphylaxis, pegvaliase is only available through a Risk Evaluation and Mitigation Strategies (REMS) program which includes prescriber and pharmacy certification requirements and patient educational enrollment. In clinical trials, most patients developed anti-PEG IgM and IgG antibodies after treatment. The clinical effects of concomitant treatment with other pegylated products are unknown. Therefore, if patients are treated in combination with other pegylated products, further monitoring for hypersensitivity reactions and anaphylaxis is recommended. ${ }^{11}$

\section{Relevance to Patient Care and Clinical Practice}

The risk of adverse outcomes in PKU is related to disease severity, blood phenylalanine concentration, and adherence to treatment. ${ }^{4}$ The assessment of blood phenylalanine concentrations may also be indicative of patient adherence to therapy. ${ }^{22}$ Poor adherence can manifest as failure to take medical foods or prescribed medications, and missing regular clinic appointments or blood phenylalanine testing. ${ }^{23} \mathrm{~A}$ presentation released by BioMarin Pharmaceuticals suggests there are 125 PKU clinics in the United States currently managing patients through dietary counseling and/or sapropterin. ${ }^{24} \mathrm{~A}$ study of $45 \mathrm{PKU}$ clinics showed that non-adherence to clinic-recommended target phenylalanine concentrations increased with age. Most adults had blood phenylalanine concentrations $>360 \mu \mathrm{mol} / \mathrm{L}$ with $15 \%$ of patients aged 18 to 29 years and $20 \%$ of patients aged $30+$ years reported to have concentrations $>1200 \mu \mathrm{mol} / \mathrm{L} .{ }^{23}$ Given that PKU can cause neurocognitive and psychiatric symptoms, there may be an unmet need for additional therapeutic approaches in adults with uncontrolled disease.

Dietary treatment consists of dietary restriction of phenylalanine, phenylalanine-free protein substitutes ( $\mathrm{L}$-amino acid mixtures), and modified low-protein foods. ${ }^{4,6}$ Patients with residual enzymatic activity of $\mathrm{PAH}$ may respond to sapropterin which increases metabolism of phenylalanine to tyrosine. Safety and efficacy of sapropterin have been established in pediatric patients as young as 1 month of age. ${ }^{21}$ Prior to routine treatment with sapropterin, a test should be conducted to determine if the patient is sapropterin-responsive, defined as a rapid decline in phenylalanine or increase in phenylalanine tolerance. Sapropterin can provide better phenylalanine control and increase dietary phenylalanine tolerance. ${ }^{25}$ Clinical guidelines have recently been updated on to address the role of pegvaliase in management of PKU. The goal of pegvaliase treatment is to provide maintenance of blood phenylalanine concentrations while normalizing diet. Pegvaliase can be considered for all adult patients with PKU who can adhere to therapy, including requirement for monitoring of AEs. ${ }^{26}$ No head-to-head trials were conducted comparing the safety and efficacy of sapropterin with pegvaliase. Given patients in the clinical trials were unable to continue sapropterin in the pegvaliase trials, it is unclear whether the combination is statistically and clinically more beneficial than either treatment alone.

Although the package insert for pegvaliase does not specify use to be in conjunction with a phenylalanine-restricted diet, it is indicated in patients with uncontrolled blood phenylalanine concentrations "on existing management" 11 which can be inferred as guideline-recommended dietary therapy and/or sapropterin pharmacotherapy. Furthermore, in pegvaliase clinical trials, patients were stable in protein intake and in many instances received counseling from a dietician. ${ }^{15-19}$ However, while Thomas et al observed stable total dietary protein intake, there was a decrease in medical food protein (from 26.3 to $18.4 \mathrm{~g} / \mathrm{d}$ ) and an increase in dietary phenylalanine intake (from 1700.2 to $2679.7 \mathrm{mg} / \mathrm{d}$ ). This shift may indicate a decreased need for medical food. ${ }^{18}$ Efficacy of pegvaliase without dietary therapy was not assessed in clinical trials. Due to the potential shifts in dosing from changing dietary protein and phenylalanine intake, continuation of nutritional and blood phenylalanine monitoring is warranted in patients treated with pegvaliase. ${ }^{11,26}$

Given only $25 \%$ to $50 \%$ of patients with PKU respond to sapropterin, ${ }^{3}$ the availability of additional pharmacologic options is necessary to improve the quality of life in patients with uncontrolled PKU. In 2015, the National PKU Alliance conducted a survey of adults and children with PKU in the United States. The survey confirmed that dietary therapy is the mainstay of clinical treatment. Approximately 6\% of survey respondents stated they were not treating PKU with medical foods or pharmacotherapy. Most survey respondents (91\%) stated the importance of development of new products for PKU. Respondents generally preferred oral therapy over injectable therapy, and home injections over injections, at a medical facility. ${ }^{27}$ Pegvaliase is a novel enzyme substitution therapy which can be used in patients with more severe disease and in part meets the needs of the PKU community. The subcutaneous prefilled syringe can be self-administered if patients demonstrate adequate competency. ${ }^{11}$ Although an oral pegylated PAL formulation has been investigated in animal studies, ${ }^{28}$ similar trials have not been conducted in humans. It is recommended that multidisciplinary teams continue involvement in 
care of patients with PKU, including monitoring therapeutic response, adverse effects, and medication adherence.

\section{Cost}

As of June 2018, pegvaliase has been launched. For cost considerations, the average wholesale price (AWP) for pegvaliasepqpz prefilled syringes are US\$585.60 which includes 3 strengths: $2.5 \mathrm{mg} / 0.5 \mathrm{~mL}, 10 \mathrm{mg} / 0.5 \mathrm{~mL}$, and $20 \mathrm{mg} / \mathrm{mL}$, whereas the AWP of sapropterin 100 and $500 \mathrm{mg}$ tablets are US $\$ 44.28$ and US\$221.40 per tablet, respectively. ${ }^{29,30}$ Using these AWP cost figures, the 30 -day cost for a $70 \mathrm{~kg}$ patient at the maximum recommended sapropterin dose $(20 \mathrm{mg} / \mathrm{kg}$ once daily) is US\$5314 and at the maximum recommended pegvaliase-pqpz dose (40 mg once daily) is US\$35136. BioMarin Pharmaceuticals predicts the average annual net cost of therapy for a typical patient to be approximately US\$192000 per year based on an average of 1.5 units per patient at maintenance dosing. ${ }^{24}$ Dietary treatments used in conjunction with currently available pharmacotherapy pose an additional cost burden to patients and payers.

\section{Conclusions}

Patient characteristics and preferences should be considered to help guide treatment of PKU. Pegvaliase reduces blood phenylalanine concentrations independent of $\mathrm{PAH}$ activity compared with previously available therapeutic alternatives. ${ }^{4}$ In pivotal phase 3 clinical studies, treatment with pegvaliase was associated with overall safety and statistically significant improvements in blood phenylalanine concentrations. ${ }^{18,19}$ Patients also had sustained reductions in blood phenylalanine concentrations that reached guideline-recommended levels. However, due to risks of anaphylaxis, pegvaliase is only available through a restricted program under REMS. ${ }^{11}$ The injectable route of administration, potential risks, and factors related to insurance coverage may limit the use of pegvaliase. At the present time, pegvaliase is only FDA-approved for use in adults who have uncontrolled blood phenylalanine concentrations $>600 \mu \mathrm{mol} / \mathrm{L} .{ }^{11}$ Clinical guidelines have been updated to address the role of pegvaliase in management of PKU. ${ }^{26}$ Given the high cost, therapy may be a viable option for patients who have failed existing management strategies due to inadequate response or desire for dietary relaxation. Further research should be conducted to evaluate the safety and efficacy in younger patients, those with milder forms of PKU, in combination with sapropterin, and with limited dietary therapy.

\section{Author Contributions}

$\mathrm{TH}$ and VAC wrote, reviewed, and approved the final manuscript.

\section{Ethical Approval}

Given there was no human participation or use of personal data involved in the writing of this review article, no ethical permission was applied for.

\section{Informed Consent}

Given the writing of this review article was non-human subject research and based on the availability of published clinical trial data, written/verbal consent from patients and/or caregivers was not necessary.

\section{ORCID iD}

Tasmina Hydery (iD https://orcid.org/0000-0002-7206-1668

\section{REFERENCES}

1. National Institutes of Health Consensus Development Panel. National Institutes of Health Consensus Development Conference Statement: phenylketonuria: screening and management, October 16-18, 2000. Pediatrics. 2001; 108:972.

2. Bodamer OA, Hahn S, TePas E. Overview of phenylketonuria. In: Basow, DS, ed. UpToDate [database on the internet]. Waltham, MA: UpToDate; 2018. http://www.utdol.com/utd/index.do. Accessed June 19, 2018.

3. Scriver CR, Kaufman S. The hyperphenylalaninemias. Phenylalanine hydroxylase deficiency. In: Scriver CR, Beaudet AL, Sly WS, Valle D, eds. The Metabolic and Molecular Bases of Inherited Disease. 8th ed. New York: McGraw-Hill; 2001:1667.

4. Vockley J, Andersson HC, Antshel KM, et al. Phenylalanine hydroxylase deficiency: diagnosis and management guideline. Genet Med. 2014;16:188-200. doi:10.1038/gim.2013.157.

5. Abadie V, Berthelot J, Feillet F, et al. [Management of phenylketonuria and hyperphenylalaninemia: the French guidelines]. Arch Pediatr. 2005;12:594. doi:10.1016/j.arcped.2005.02.004.

6. van Wegberg AMJ, MacDonald A, Ahring K, et al. The complete European guidelines on phenylketonuria: diagnosis and treatment. Orphanet J Rare Dis. 2017;12:162. doi:10.1186/s13023-017-0685-2.

7. van Spronsen FJ, Burgard P. The truth of treating patients with phenylketonuria after childhood: the need for a new guideline. J Inherit Metab Dis. 2008;31:673679. doi:10.1007/s10545-008-0918-6.

8. BioMarin Announces FDA Approval for Kuvan. BioMarin. https://investors. biomarin.com/2007-12-13-BioMarin-Announces-FDA-Approval-for-Kuvan. Accessed September 26, 2018.

9. Somaraju UR, Merrin M. Sapropterin dihydrochloride for phenylketonuria Cochrane Database Syst Rev. 2015;3:CD008005. doi:10.1002/14651858. CD008005.pub4.

10. FDA approves a new treatment for PKU, a rare and serious genetic disease. Food and Drug Administration. https://www.fda.gov/newsevents/newsroom/pressannouncements/ucm608835.htm. Accessed September 26, 2018.

11. Palynziq ${ }^{\circledR}$ [package insert]. Novato, CA: BioMarin Pharmaceutical Inc; May 2018.

12. Palynziq ${ }^{\circledR}$ (pegvaliase-pqpz) formulary dossier. BioMarin, Data on file.

13. Bell SM, Wendt DJ, Zhang Y, et al. Formulation and PEGylation optimization of the therapeutic PEGylated phenylalanine ammonia lyase for the treatment of phenylketonuria. PLOS ONE. 2017;12:e173269. doi:10.1371/journal. pone.0173269.

14. Sarkissian CN, Shao Z, Blain F, et al. A different approach to treatment of phenylketonuria: phenylalanine degradation with recombinant phenylalanine ammonia lyase. Proc Natl Acad Sci U S A. 1999;96:2339-2344. doi:10.1073/ pnas.96.5.2339.

15. Longo N, Harding CO, Burton BK, Grange DK, et al. Single-dose, subcutaneous recombinant phenylalanine ammonia lyase conjugated with polyethylene glycol in adult patients with phenylketonuria: an open-label, multicenter, phase 1 dose-escalation trial. Lancet. 2014;384:37-44. doi:10.1016/S0140 $-6736(13) 61841$.

16. Thomas JA, Longo N, Zori R, Burton BK, et al. Evaluation of multiple dosing regimens in phase 2 studies of "rAvPAL-PEG" for control of blood phenylalanine levels in adults with phenylketonuria. Paper presented at: Society for the Study of Inborn Errors of Metabolism (SSIEM) Annual Symposium, Lyon, France, 1-4 September 2015, P-149.

17. Zori R, Thomas JA, Shur N, et al. Induction, titration, and maintenance dosing regimen in a phase 2 study of pegvaliase for control of blood phenylalanine in adults with phenylketonuria. Mol Genet Metab. 2018;125:217-227. doi:10.1016/j. ymgme.2018.06.010.

18. Thomas J, Levy H, Amato S, et al. Pegvaliase for the treatment of phenylketonuria: Results of a long-term phase 3 clinical trial program (PRISM). Mol Genet Metab. 2018;124:27-38. doi:10.1016/j.ymgme.2018.03.006.

19. Harding CO, Amato RS, Stuy M, et al. Pegvaliase for the treatment of phenylketonuria: a pivotal, double-blind randomized discontinuation phase 3 
clinical trial. Mol Genet Metab. 2018;124:20-26. doi:10.1016/j.ymgme.2018 .03.003.

20. van Rijn M, Hoeksma M, Sauer PJ, Modderman P, Reijngoud DJ, van Spronsen FJ. Adult patients with well-controlled phenylketonuria tolerate incidental additional intake of phenylalanine. Ann Nutr Metab. 2011;58:94-100. doi:10.1159 1000324924.

21. Kuvan ${ }^{\circledR}$ [package insert]. Novato, CA: BioMarin Pharmaceutical Inc; August 2016.

22. MaCdonald A, van Rijn M, Feillet F, et al. Adherence issues in inherited metabolic disorders treated by low natural protein diets. Ann Nutr Metab. 2012;61:289295. doi:10.1159/000342256.

23. Jurecki ER, Cederbaum S, Kopesky J, et al. Adherence to clinic recommendations among patients with phenylketonuria in the United States. Mol Genet Metab. 2017;120:190-197. doi:10.1016/j.ymgme.2017.01.001.

24. BioMarin Pharmaceuticals. Conference Call to Discuss Approval of Palynziq. investors.biomarin.com/download/Palynziq+Approval+Presentation_052418. pdf. Accessed September 27, 2018.
25. Cunningham A, Bausell H, Brown M, et al. Recommendations for the use of sapropterin in phenylketonuria. Mol Genet Metab. 2012;106:269-276. doi:10.1016/j.ymgme.2012.04.004.

26. Longo N, Dimmock D, Levy H, et al. Evidence- and consensus-based recommendations for the use of pegvaliase in adults with phenylketonuria. Genet Med. 2018. doi:10.1038/s41436-018-0403-z.

27. Brown CS, Lichter-Konecki U. Phenylketonuria (PKU): a problem solved. Mol Genet Metab Rep. 2016;6:8-12. doi:10.1016/j.ymgmr.2015.12.004.

28. Sarkissian CN, Kang TS, Gamez A, Scriver CR, Stevens RC. Evaluation of orally administered PEGylated phenylalanine ammonia lyase in mice for the treatment of phenylketonuria. Mol Genet Metab. 2011;104:249-254. doi:10.1016 /j.ymgme.2011.06.016.

29. Pegvaliase-pqpz. In: Basow DS, ed. UpToDate [database on the internet]. Waltham, MA: UpToDate; 2018. http://www.utdol.com/utd/index.do. Accessed September 26, 2018.

30. Sapropterin. In: Basow DS, ed. UpToDate [database on the internet]. Waltham, MA: UpToDate; 2018. http://www.utdol.com/utd/index.do. Accessed September 26, 2018. 